\title{
Pharmacometrics of 3-Methoxypterostilbene: A Component of Traditional Chinese Medicinal Plants
}

\author{
Stephanie E. Martinez, Casey L. Sayre, and Neal M. Davies \\ Faculty of Pharmacy, Apotex Centre University of Manitoba, Winnipeg, MB, Canada R3E 0T5 \\ Correspondence should be addressed to Neal M. Davies; neal.davies@ad.umanitoba.ca
}

Received 9 February 2013; Accepted 26 March 2013

Academic Editor: Srinivas Nammi

Copyright (C) 2013 Stephanie E. Martinez et al. This is an open access article distributed under the Creative Commons Attribution License, which permits unrestricted use, distribution, and reproduction in any medium, provided the original work is properly cited.

3-Methoxypterostilbene is a naturally occurring stilbene with potential in the treatment of diabetes. The preclinical pharmacokinetics and pharmacodynamics of 3-methoxypterostilbene were evaluated in the present study. The right jugular veins of male SpragueDawley rats were cannulated. The rats were dosed $10 \mathrm{mg} / \mathrm{kg}$ or $100 \mathrm{mg} / \mathrm{kg}$ of 3-methoxypterostilbene intravenously (IV) or orally (PO), respectively. Serum and urine samples were analyzed using a previously validated reversed-phase HPLC method. Serum AUC, serum $t_{1 / 2}$, urine $t_{1 / 2}, \mathrm{Cl}_{\text {total }}$, and Vd for IV dosing were $48.1 \pm 23.8 \mu \mathrm{g} / \mathrm{h} / \mathrm{mL}, 18.9 \pm 10.9 \mathrm{~h}, 9.54 \pm 1.51 \mathrm{~h}, 47.8 \pm 23.7 \mathrm{~L} / \mathrm{h} / \mathrm{kg}$, and $5.11 \pm 0.38 \mathrm{~L} / \mathrm{kg}$, respectively (mean $\pm \mathrm{SEM}, n=4$ ). Serum AUC, serum $t_{1 / 2}$, urine $t_{1 / 2}, \mathrm{Cl}_{\text {total }}$, and Vd for PO dosing were $229 \pm 44.6 \mu \mathrm{g} / \mathrm{h} / \mathrm{mL}, 73.3 \pm 8.91 \mathrm{~h}, 20.6 \pm 3.01 \mathrm{~h}, 0.48 \pm 0.008 \mathrm{~L} / \mathrm{h} / \mathrm{kg}$, and $52.0 \pm 10.5 \mathrm{~L} / \mathrm{kg}$, respectively $(\mathrm{mean} \pm \mathrm{SEM}, n=4)$. Bioavailability of the stilbene was determined to be $50.6 \% \pm 10.0 \%$. A 3-methoxypterostilbene glucuronidated metabolite was detected in both serum and urine. 3-Methoxypterostilbene exhibited antidiabetic activity including $\alpha$-glucosidase and $\alpha$-amylase inhibition as well as concentration-dependent antioxidant capacity similar to resveratrol. 3-Methoxypterostilbene also exhibited anti-inflammatory activity. 3-Methoxypterostilbene appears to be a bioactive compound and may be useful in reducing postprandial hyperglycemia.

\section{Introduction}

3-Methoxypterostilbene (trans-3,3' -5-trimethoxy- $4^{\prime}$-hydroxystilbene), $\mathrm{C}_{17} \mathrm{H}_{18} \mathrm{O}_{4}, \quad \mathrm{MW} 286.324 \mathrm{~g} / \mathrm{mol}$ (Figure 1), is a naturally occurring stilbene $[1,2]$ that can also be easily synthesized using simple combinatorial synthesis [3-7]. 3-Methoxypterostilbene is a structural analogue of resveratrol, which has demonstrated a myriad of potential prohealth effects including anticancer, cardioprotective, antiinflammatory, neuroprotective, and antiobesity properties [8]. However, it differs from resveratrol in its physicochemical properties. The predicted octanol water partition coefficient (XLogP) for 3-methoxypterostilbene is $3.54 \pm 0.49$ [9] and the experimentally determined $\mathrm{XLogP}$ for resveratrol is $1.53 \pm 0.01[10]$.

3-Methoxypterostilbene has been isolated in two plants used in traditional Chinese medicine. The compound has been found in Sphaerophysa salsula (also known as Swainsona salsula), a shrub called "ku ma du," used for the treatment of hypertension [1]. 3-Methoxypterostilbene has also been found as an aglycone of a stilbene glycoside in the commonly used Rheum palmatum (Chinese rhubarb), called "da huang," used to treat digestive disorders [2].

Due to 3-methoxypterostilbene's structural similarity to resveratrol and its presence in traditional Chinese medicinal plants, 3-methoxypterostilbene may also possess potential health benefits. However, information in the literature on the bioactivity of 3-methoxypterostilbene is scant. In a report seeking to identify biologically active piceatannol (another structural analogue of resveratrol) analogs with greater stability than piceatannol, 3-methoxypterostilbene was reported to demonstrate significantly greater activity in a $9 \mathrm{~KB}$ cytotoxicity assay as well as a crown-gall plant antitumor (potato disk) assay than piceatannol [3]. 3-Methoxypterostilbene proved to be as effective as resveratrol in the inhibition of bacterial lipopolysaccharide-induced tissue factor expression in human peripheral blood mononuclear cells in a 


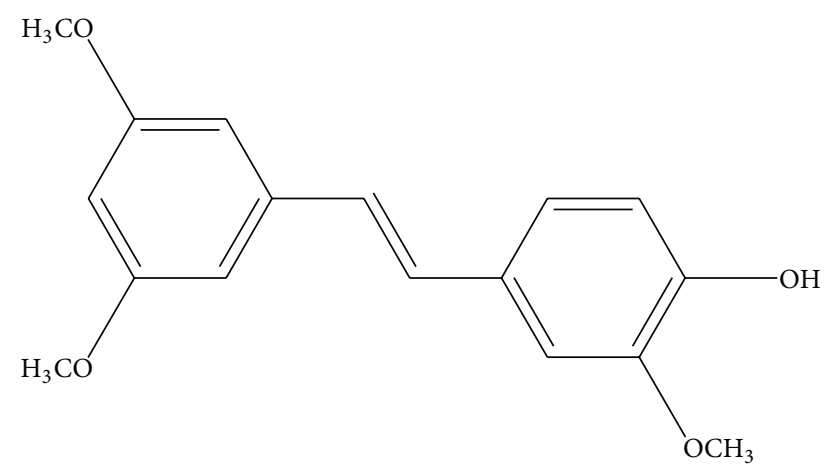

Figure 1: Chemical structure of 3-methoxypterostilbene.

study investigating resveratrol derivatives and coronary heart disease [11]. Several studies have also demonstrated that 3methoxypterostilbene possesses greater apoptotic-inducing activity than resveratrol in human leukemia-derived HL60 cells $[4,12,13]$.

With the ever-increasing natural products canon of knowledge and growing concern for obesity-related diseases, there has been much focus on the use of natural products to aid in the management and treatment of type 2 diabetes. Resveratrol has been extensively studied in animals for its potential to treat obesity and type 2 diabetes [8]. Resveratrol appears to be able to increase insulin sensitivity in various animal models of insulin resistance [14-18]. Additionally, animal studies using models that consisted of genetically obese rats and mice with dietary induced obesity or chemically induced diabetes found that resveratrol reduced blood glucose levels, which is important in the management of type 2 diabetes and prediabetic patients [14, 15, 19-25]. Thus, structural analogues of resveratrol may also possess antidiabetic properties similar to those of resveratrol.

To our knowledge, there have been no studies evaluating the pharmacokinetics, disposition, or the in vivo metabolism of 3-methoxypterostilbene other than that of a single rat previously reported by Martinez et al. [9]. The objectives of the present study are to examine the pharmacokinetic disposition of 3-methoxypterostilbene as well as its in vivo metabolism and antidiabetic properties. To facilitate this, a reversed-phase high-performance liquid chromatographic (RP-HPLC) method was developed and validated for quantification of 3-methoxypterostilbene in biological matrices using ultraviolet detection [9]. Additionally, the objectives of this study were to investigate select biological activities of 3-methoxypterostilbene and perform a content analysis on commercially available dried traditional Chinese herbs reported to contain 3-methoxypterostilbene using the previously validated RP-HPLC method. For the first time, to our knowledge, the preclinical pharmacokinetics, antioxidant activity, cyclooxygenase- 1 and -2 (COX-1 and -2) inhibition, and $\alpha$-glucosidase and $\alpha$-amylase inhibitory activity of 3 methoxypterostilbene are reported.

\section{Materials and Methods}

2.1. Chemicals and Reagents. 3-Methoxypterostilbene was provided by the Sabinsa Corporation (Piscataway, NJ, USA) and pinosylvin was purchased from Sequoia Research Products Ltd. (Oxford, UK). HPLC-grade acetonitrile and water were purchased from J. T. Baker (Phillipsburg, NJ, USA). $\beta$-Glucuronidase type IX A ( $\beta$-glucuronidase), poly(ethylene glycol) (PEG) 400, dimethyl sulfoxide (DMSO), $\alpha$-glucosidase from Saccharomyces cerevisiae, 4-nitrophenyl $\alpha$-D-glucopyranoside, 4-(2-hydroxyethyl)1-piperazineethanesulfonic acid (HEPES), resveratrol, ibuprofen, etodolac, and $\alpha$-amylase from porcine pancreas type VI-B were purchased from Sigma-Aldrich (St. Louis, MO, USA). Amylase HR reagent was purchased from Megazyme International Ireland (Wicklow, Ireland). $\beta$-Glucosidase from almonds was purchased from Tokyo Chemical Industry Co., Ltd. (Tokyo, Japan). Dried Swainsona salsula extract was provided by DaXingAnLing Snow Lotus Herb Bio-technology Co., Ltd. (Heilongjiang, China) and dried da huang (Chinese rhubarb) was purchased from Kwok Shing Ent. Ltd. (Scarborough, ON, Canada). The antioxidant activity kit and cyclooxygenase- 1 and -2 inhibitor screening kits were purchased from Cayman Chemical Company (Ann Arbor, MI, USA).

2.2. Chromatographic System and Conditions. The HPLC system used was a Shimadzu HPLC (Kyoto, Japan), consisting of two LC-10A pumps, a SIL-10AF autoinjector, a SPDM10A photodiode array detector, and a SCL-10A system controller. Data collection and integration were achieved using Shimadzu EZ Start Class VP (version 7.4) software. A Phenomenex Luna $\mathrm{C}_{18}(2)(5 \mu \mathrm{m}, 250 \times 4.60 \mathrm{~mm})$ column was used. The mobile phase consisted of acetonitrile and water $(62: 38 \mathrm{v} / \mathrm{v})$ that were filtered and degassed under reduced pressure prior to use. Pinosylvin was used as the internal standard. Isocratic separation at ambient temperature using a flow rate of $1.05 \mathrm{~mL} / \mathrm{min}$ was employed. Ultraviolet detection was carried out at $327 \mathrm{~nm}$. Validation indicated that the precision of the assay was $<12 \%$ (RSD) and was within $12 \%$ at the limit of quantification (LOQ) $(0.05 \mu \mathrm{g} / \mathrm{mL})$. The bias of the assay was $<15 \%$ and was within $13 \%$ at the LOQ [9].

2.3. Animals and Surgical Procedures. Male Sprague-Dawley rats $(\approx 200 \mathrm{~g})$ were obtained from Simonsen Laboratories (Gilroy, CA, USA) and allowed food (Purina Rat Chow 5001) and water ad libitum upon arrival to the vivarium. Rats were housed in a temperature- and humidity-controlled facility with a $12 \mathrm{~h}$ light/dark cycle. Prior to the first day of the pharmacokinetic experiment, the rats were anesthetized using isoflurane (IsoFlo, Abbott Laboratories, Abbot Park, IL, USA) coupled with an oxygen regulator, and monitored by pedal reflex and respiration rate to maintain a surgical plane of anesthesia. The right jugular veins of the rats were cannulated with sterile silastic cannulas (Dow Corning, Midland, MI, USA). After cannulation, Intramedic PE50 polyethylene tubing (Becton, Dickinson and Company, Franklin Lakes, NJ, USA) was exposed through the dorsal 
skin. The cannulas were flushed with nonheparinized $0.9 \%$ sterile saline solution. The animals were placed in metabolic cages to recover and fasted overnight.

Animal ethics approval was obtained from the University of Manitoba Office of Research Ethics and Compliance.

2.4. Dosages. No pharmacokinetics studies are reported in the literature for 3-methoxypterostilbene. Despite the paucity of 3-methoxypterostilbene pharmacokinetic studies in the literature, studies on other stilbenes have reported intravenous (IV) dosage ranges from 10 to $20 \mathrm{mg} / \mathrm{kg}$ [26-30] and from 50 to $300 \mathrm{mg} / / \mathrm{kg}$ for oral (PO) dosage [27, 31,32]. In keeping with the literature, doses of $10 \mathrm{mg} / \mathrm{kg}$ IV and $100 \mathrm{mg} / \mathrm{kg}$ PO were chosen.

2.5. Pharmacokinetic Study. Male Sprague-Dawley rats $(n=$ 8 , average weight $200 \mathrm{~g}$ ) were cannulated as described in the Animals and Surgical Procedures section. The animals were placed in metabolic cages following surgery where they were recovered overnight and fasted for $12 \mathrm{~h}$ prior to dosing. On the day of the experiment, the animals were dosed with 3methoxypterostilbene in PEG 400 either IV $(10 \mathrm{mg} / \mathrm{kg}, n=4)$ or PO $(100 \mathrm{mg} / \mathrm{kg}, n=4)$. After dosing, a series of whole blood samples $(0.5 \mathrm{~mL})$ were collected at 0,1 , and $15 \mathrm{~min}$, and $0.5,1,2,4,6,12,24,48$, and $72 \mathrm{~h}$ and $0,0.25,0.5,1,2,4,6$, $12,24,48$, and $72 \mathrm{~h}$ for IV and PO dosed rats, respectively. The cannulas were flushed with $0.5 \mathrm{~mL} 0.9 \%$ nonheparinized saline solution after each sample collection. The samples were collected into regular $2.0 \mathrm{~mL}$ Eppendorf tubes, centrifuged at $10,000 \mathrm{rpm}$ for $5 \mathrm{~min}$ (Beckman Microfuge centrifuge, Beckman Coulter Inc., Fullerton, CA, USA), and the serum was collected. The serum was divided into two $0.1 \mathrm{~mL}$ fractions and placed into regular $2.0 \mathrm{~mL}$ Eppendorf tubes labeled as free and total serum samples. Samples were stored at $-20^{\circ} \mathrm{C}$ until analyzed. Urine samples were also collected at $0,2,6,12,24,48$, and $72 \mathrm{~h}$ following 3-methoxypterostilbene administration. The volumes of urine produced by the rats were recorded, and two $0.1 \mathrm{~mL}$ aliquots were collected into separate prelabeled regular polypropylene microcentrifuge tubes and labeled as free and total urine samples and stored at $-20^{\circ} \mathrm{C}$ until analyzed. At $72 \mathrm{~h}$ after dose, the animals were euthanized exsanguinated, and serum was collected.

2.6. Serum and Urine Sample Preparation. Serum and urine samples $(0.1 \mathrm{~mL})$ were run in duplicate with or without the addition of $20 \mu \mathrm{L}$ of $500 \mathrm{U} / \mathrm{mL} \beta$-glucuronidase and incubated in a shaking water bath at $37^{\circ} \mathrm{C}$ for $2 \mathrm{~h}$ to liberate any glucuronide conjugates [33]. The proteins present in the serum samples were precipitated using $1 \mathrm{~mL}$ of $-20^{\circ} \mathrm{C}$ acetonitrile. Urine and serum samples were vortexed (Vortex Genie-2, VWR Scientific, West Chester, PA, USA) for $30 \mathrm{~s}$ and centrifuged at $10,000 \mathrm{rpm}$ for $5 \mathrm{~min}$. The supernatants were transferred to new, labeled $2.0 \mathrm{~mL}$ Eppendorf microcentrifuge tubes. The samples were evaporated to dryness by a stream of nitrogen gas. The residues were reconstituted with $200 \mu \mathrm{L}$ of mobile phase, vortexed for $30 \mathrm{~s}$, and centrifuged at $10,000 \mathrm{rpm}$ for $5 \mathrm{~min}$. The supernatants were transferred to
HPLC vials, and $100 \mu \mathrm{L}$ was injected into the HPLC system for each sample.

$\beta$-Glucuronidase from E. colitype IX-A acts to specifically cleave the sugar moiety attached to the parent compound from the 3-methoxypterostilbene glucuronide back into the aglycone (3-methoxypterostilbene). The samples which did not undergo enzymatic hydrolysis (free samples) were utilized to determine the concentration of the aglycone, whereas the samples that did undergo enzymatic hydrolysis (total samples) were used to determine the concentration of the aglycone originally present in the sample in addition to the concentration of the glucuronidated metabolite cleaved back to 3-methoxypterostilbene. Therefore, by subtracting the free sample concentration from the total sample concentration, the concentration of the glucuronidated metabolite can be calculated without the use of an additional chromatographic run and analysis.

2.7. Pharmacokinetic Analysis. Pharmacokinetic analysis was performed using data from individual rats for which the mean and standard error of the mean (SEM) were calculated for each group. Samples were analyzed using WinNonlin software (version 1.0; Pharsight Corporation, Mountain View, CA, USA) to calculate the pharmacokinetic parameters. The rats' concentrations versus time points were subjected to a noncompartmental model. The apparent elimination rate constant (KE) was estimated from the slope of the log-linear phase of declining concentration versus time plot. The halflife and rate of eliminated were determined by applying the previously described software with the specified parameters. The renal clearance was calculated by multiplying the fraction of compound excreted unchanged with total body clearance. The plasma half-life $\left(t_{1 / 2}\right)$ was determined using the following equation: $t_{1 / 2}=0.693 / \mathrm{KE}$. To determine the fraction of unchanged 3-methoxypterostilbene excreted $\left(f_{e}\right)$ in urine, the total amount of urine was divided by the total dose administered. The renal clearance $\left(\mathrm{CL}_{\text {renal }}\right)$ was determined by the equation: $\mathrm{CL}_{\text {renal }}=f_{e} \times \mathrm{CL}_{\text {total }}$.

\subsection{Content Analysis of Dried Traditional Chinese Medicinal} Plants. 3-Methoxypterostilbene has been reported to be present in two plants used in traditional Chinese medicineSphaerophysa salsula (Swainsona salsula) and Rheum palmatum (Chinese rhubarb) [1,2]. Dried $S$. salsula extract and dried Chinese rhubarb are both commercially available products. Chinese rhubarb was frozen under liquid nitrogen and then ground into a fine powder. $S$. salsula extract was already in powdered form. Two $0.1 \mathrm{~g}$ of each product were measured and placed into $2.0 \mathrm{~mL}$ Eppendorf tubes. $1.5 \mathrm{~mL}$ methanol was added to each tube for extraction. Tubes were vortexed for 30 seconds, agitated for $3 \mathrm{~h}$, and centrifuged at $10,000 \mathrm{rpm}$ for $5 \mathrm{~min}$. One of the duplicates was treated to extract only aglycones (free) and the second of the duplicates was treated to cleave any glycosides to aglycones (total) by using $\beta$-glucosidase from almonds. The supernatants from the free samples were transferred into new $2.0 \mathrm{~mL}$ Eppendorf tubes, and $50 \mu \mathrm{L}$ of internal standard, pinosylvin, was added. Samples were vortexed for $30 \mathrm{~s}$, dried to completion under 
a stream of nitrogen gas, and stored at $-20^{\circ} \mathrm{C}$ until analysis. The supernatants of the total samples were transferred to new $2.0 \mathrm{~mL}$ Eppendorf tubes, dried to completion under a stream of compressed nitrogen gas, and reconstituted with PBS (200 $\mu \mathrm{L}$ at $\mathrm{pH} 7.4) .20 \mu \mathrm{L}$ of $\beta$-glucosidase $(750 \mathrm{U} / \mathrm{mL}$ in $\mathrm{PBS}$ at $\mathrm{pH}$ 7.4) was added and samples were incubated for $48 \mathrm{~h}$ at $37^{\circ} \mathrm{C}$ in a shaking water bath. $\beta$-Glucuronidase acts by cleaving the glycosidic sugar moieties frequently present in plant extracts as previously described [29]. Acetonitrile $(1 \mathrm{~mL})$ was added to stop the enzymatic reaction, followed by the addition of internal standard $(50 \mu \mathrm{L})$. Samples were centrifuged at 10,000 rpm for $5 \mathrm{~min}$ and the supernatant was dried to completion under a stream of compressed nitrogen gas. Both free and total samples were reconstituted in mobile phase $(200 \mu \mathrm{L})$, and $100 \mu \mathrm{L}$ was injected into the HPLC under the same conditions previously described.

2.9. Antioxidant Capacity Determination. The antioxidant capacities of 3-methoxypterostilbene and resveratrol were measured through an assay that relied on the inhibition of the oxidation of ABTS (2,2' -azino-di-[3-ethylbenzthiazoline sulphonate]) to $\mathrm{ABTS}^{\bullet+}$ by metmyoglobin. The amount of $\mathrm{ABTS}^{\circ+}$ can be monitored spectrophotometrically. The degree of suppression of absorbance caused by the compound of interest is proportional to the concentration of ABTS $^{\bullet+}$, which is expressed as Trolox equivalents $(\mu \mathrm{g} / \mathrm{mL})$. For this assay, 3-methoxypterostilbene and resveratrol were dissolved in DMSO on the day of the experiment to yield concentrations of $1,5,10,50$, and $100 \mu \mathrm{g} / \mathrm{mL}$. No additional dilution was employed. To run the assay, $10 \mu \mathrm{L}$ of sample was combined with $10 \mu \mathrm{L}$ metmyoglobin and $150 \mu \mathrm{L}$ chromogen. Then, $40 \mu \mathrm{L}$ of hydrogen peroxide working solution was added within $1 \mathrm{~min}$ to all the samples. The plate was covered and incubated on a shaker for $5 \mathrm{~min}$ at room temperature 923 $\left.\pm 1^{\circ} \mathrm{C}\right)$, and the absorbance was measured at $750 \mathrm{~nm}$ using the Synergy HT multiwell plate reader and Gen5 data analysis software (Biotek Instruments Inc., Winooski, VT, USA). The assay was performed in quadruplet. For more information regarding the assay protocol, please refer to the instructions for the kit (Antioxidant Assay Kit from Cayman ChemicalCat. no. 709091).

2.10. Cyclooxygenase Inhibition Determination. The inhibition of COX-1 and -2 by 3-methoxypterostilbene was measured through the use of a three-day commercial assay kit. The assay relied on the quantification of the prostanoid product based on enzyme immunoassay (EIA), which uses a nonspecific antibody for prostaglandins (PGs). The constant concentration of the PG-AChE-tracer and the varying concentrations of the PGs available to bind to the antiserum is inversely proportional to the concentration of free PGs in the well. For this assay, 3-methoxypterostilbene was dissolved in DMSO over the concentration range of 1-250 $\mu \mathrm{g} / \mathrm{mL}$. Ibuprofen and etodolac, COX-2 preferential NSAIDs, were dissolved in DMSO and used as controls over the concentration range of $1-250 \mu \mathrm{g} / \mathrm{mL}$. Reagents were prepared according to the manufacturer's instructions that accompanied the kit. The ELISA plate for this purpose was read at an absorbance of
$415 \mathrm{~nm}$ within 10 minutes at room temperature $\left(23 \pm 1^{\circ} \mathrm{C}\right)$ using the Synergy HT multiwell plate reader and Gen5 data analysis software (Biotek Instruments Inc., Winooski, VT, USA). The assay was performed in quadruplet. For more information regarding the assay protocol, please refer to the instructions for the kit (COX Inhibitor Screening Assay Kit from Cayman Chemical-Cat. no. 560131).

2.11. $\alpha$-Glucosidase Inhibition Determination. Inhibition of $\alpha$-glucosidase was determined through a colorimetric assay adapted and modified from the method presented by Tadera et al. [34]. The assay uses $p$-nitrophenyl- $\alpha$-Dglucopyranoside (PNPG), which is hydrolyzed specifically by $\alpha$-glucosidase into a yellow-colored product ( $p$-nitrophenol). The absorbance at $410 \mathrm{~nm}$ of liberated $p$-nitrophenol was measured. For this assay, 3-methoxypterostilbene and resveratrol were dissolved in DMSO to create concentration ranges from 0 to $200 \mu \mathrm{g} / \mathrm{mL}$. $160 \mu \mathrm{L}$ of $100 \mathrm{mM}$ phosphate buffer (pH 6.8), $25 \mu \mathrm{L}$ of $20 \mathrm{mM}$ PNPG in phosphate buffer, and $10 \mu \mathrm{L}$ of stilbenes in DMSO were added to wells of a 96well plate (10 $\mu \mathrm{L}$ DMSO was added to the control wells). The plate was incubated at $30^{\circ} \mathrm{C}$ for $5 \mathrm{~min}$ and then $10 \mu \mathrm{L}$ of the buffer containing $0.02 \mathrm{mg} / \mathrm{mL}$ of enzyme was added to each well. The plate was further incubated for $5 \mathrm{~min} .20 \mu \mathrm{L}$ of $3.25 \mathrm{M}$ sodium hydroxide was added to each well to stop the reaction. The plate was immediately read at an absorbance of $410 \mathrm{~nm}$ at room temperature $\left(23 \pm 1^{\circ} \mathrm{C}\right)$ using the Synergy HT multiwell plate reader and Gen5 data analysis software (Biotek Instruments Inc., Winooski, VT, USA). The assay was performed in sextuplicate.

Inhibition (\%) was calculated as $((A-B) / A) \times 100$, where $A$ was the average absorbance of the control wells and $B$ was the absorbance of the wells containing stilbenes.

\subsection{Alpha-Amylase Inhibition Determination. Inhibition of} $\alpha$-amylase was determined through a colorimetric assay also adapted and modified from the method presented by Tadera et al. [34]. A synthetic substrate, nonreducing-endblocked $p$-nitrophenyl maltoheptaoside (BPNPG7) commercially prepared as amylase HR reagent, which is hydrolyzed specifically by $\alpha$-amylase into $p$-nitrophenyl maltosaccharide is employed. The $\alpha$-glucosidase present in the assay then converts the new substrate into $p$-nitrophenol and absorbance at $410 \mathrm{~nm}$ is measured as previously stated in the $\alpha$-amylase assay. 3-methoxypterostilbene and resveratrol were dissolved in methanol to create concentration ranges from 0 to $200 \mu \mathrm{g} / \mathrm{mL}$. $100 \mu \mathrm{L}$ of amylase HR reagent (prepared following directions accompanying the reagent, Megazyme Amylase HR Reagent, Cat. no. R-AMHR4), and $40 \mu \mathrm{L}$ of stilbene in methanol were added to a 96 -well plate $(40 \mu \mathrm{L}$ of methanol was added to the control wells). The plate was incubated for 5 minutes at $37^{\circ} \mathrm{C}$ and then $60 \mu \mathrm{L}$ of $0.1 \mathrm{mg} / \mathrm{mL}$ $\alpha$-amylase in $0.1 \mathrm{M}$ HEPES buffer ( $\mathrm{pH}$ 6.9) was added to the reaction mixture. After further incubation at $37^{\circ} \mathrm{C}$, for $10 \mathrm{~min}, 20 \mu \mathrm{L}$ of $3.25 \mathrm{M}$ sodium hydroxide was added to each well to stop the reaction. The liberated $p$-nitrophenol was determined and the percent inhibition calculated as 


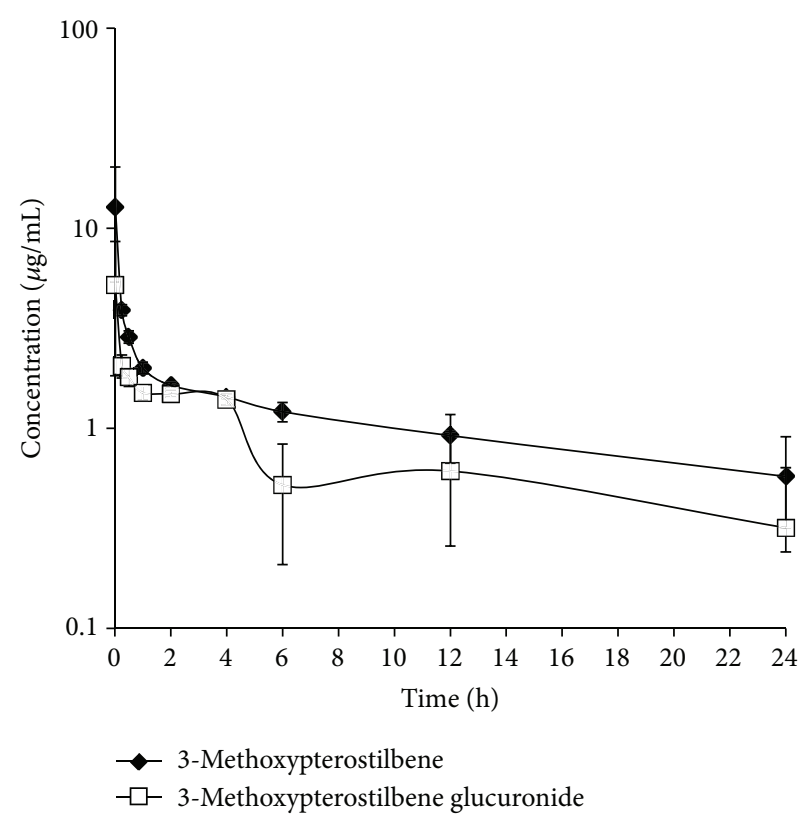

(a)

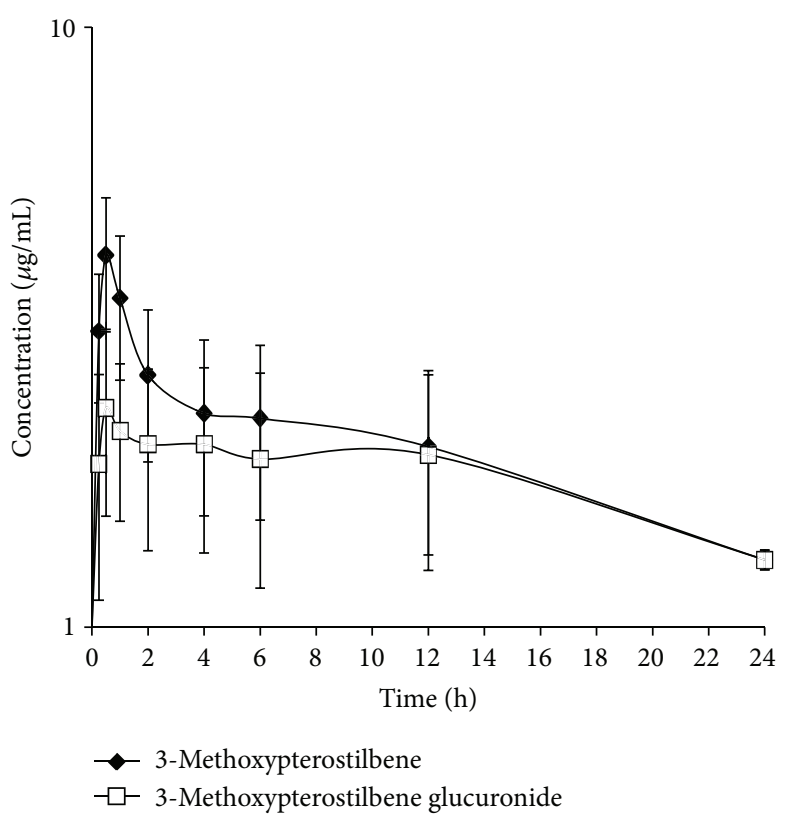

(b)

FIGURE 2: (a) 3-Methoxypterostilbene disposition in serum following intravenous administration. (b) 3-Methoxypterostilbene disposition in serum following oral administration $(n=4$, mean \pm SEM).

described in the assay for $\alpha$-glucosidase activity previously described. The assay was performed in sextuplicate.

2.13. Statistical Analysis. Compiled data were presented as mean and standard error of the mean (mean \pm SEM). Where possible, the data were analyzed for statistical significance using Minitab 15 statistical software (Minitab, Inc., State College, PA, USA). Student's $t$-test was employed for unpaired samples with a value of $P<0.05$ being considered statistically significant.

\section{Results and Discussion}

3.1. Pharmacokinetic Study. Standard curves established linearity over the concentration range studied for the serum and urine samples. Chromatograms showed no interference from endogenous components. Total samples (incubated with $\beta$-glucuronidase from Escherichia coli type IXA) verified the presence of a glucuronidated metabolite based on the increase in 3-methoxypterostilbene (aglycone parent compound) concentrations after enzymatic hydrolysis in both serum and urine. Glucuronidation of 3methoxypterostilbene parallels previous rat and human studies with resveratrol existing predominately in its conjugated form in both plasma and urine [35].

The serum concentration versus time profile for IVdosed 3-methoxypterostilbene demonstrates a rapid decline in concentration in the first hour, representing a distribution phase, which was followed by a steady elimination up to 24 hours, after which the serum concentrations were below detectable concentrations $(0.05 \mu \mathrm{g} / \mathrm{mL})$ (Figure $2(\mathrm{a})$ ). 3-Methoxypterostilbene dosed PO displayed rapid absorption with an average $T_{\max }$ of 30 minutes (Figure 2(b)). The
TABLE 1: Pharmacokinetic parameters of 3-methoxypterostilbene in the rat.

\begin{tabular}{lcc}
\hline Pharmacokinetic parameter & $\begin{array}{c}\text { Intravenous } \\
\text { Mean } \pm \text { SEM }\end{array}$ & $\begin{array}{c}\text { Oral } \\
\text { Mean } \pm \text { SEM }\end{array}$ \\
\hline $\mathrm{AUC}_{\text {inf }}(\mu \mathrm{g} \cdot \mathrm{h} / \mathrm{mL})$ & $48.1 \pm 23.8$ & $229 \pm 44.6$ \\
$\mathrm{Vd}_{\beta}(\mathrm{L} / \mathrm{kg})$ & $5.11 \pm 0.380$ & $52.0 \pm 10.5$ \\
$\mathrm{CL}_{\text {hepatic }}(\mathrm{L} / \mathrm{h} / \mathrm{kg})$ & $47.1 \pm 23.3$ & $0.480 \pm 0.0800$ \\
$\mathrm{CL}_{\text {renal }}(\mathrm{L} / \mathrm{h} / \mathrm{kg})$ & $0.760 \pm 0.460$ & $0.0100 \pm 0.000$ \\
$\mathrm{CL}_{\text {total }}(\mathrm{L} / \mathrm{h} / \mathrm{kg})$ & $47.8 \pm 23.7$ & $0.480 \pm 0.0800$ \\
$f_{e}(\%)$ & $1.64 \pm 0.950$ & $1.24 \pm 0.160$ \\
$t_{1 / 2}(\mathrm{~h})$ serum & $18.9 \pm 10.9$ & $73.3 \pm 8.91$ \\
$t_{1 / 2}(\mathrm{~h})$ urine & $9.54 \pm 1.51$ & $20.6 \pm 3.01$ \\
MRT (h) & $26.0 \pm 15.0$ & $105 \pm 13.1$ \\
Bioavailability (F\%) & 100 & $50.6 \pm 10.0$ \\
\hline
\end{tabular}

glucuronidated metabolite in both routes of administration appeared to display multiple peaking which is suggestive of enterohepatic recycling as indicated by an increase in serum concentration around $4 \mathrm{~h}$ after dose. Enterohepatic recycling has previously been reported for resveratrol $[27,36]$.

Table 1 summarizes the pharmacokinetic parameters exhibited by 3-methoxypterostilbene at an IV dose of $10 \mathrm{mg} / \mathrm{kg}$ and a PO dose of $100 \mathrm{mg} / \mathrm{kg}$. Noncompartmental analysis in WinNonlin software (ver. 1.0) was used to model both serum and urine data. The total serum clearance of 3-methoxypterostilbene was determined to be $47.8 \pm$ 23.7 L/h/kg for IV dosing and $0.480 \pm 0.0800$ for PO dosing. The mean fraction excreted in urine unchanged $\left(f_{e}\right)$ was 


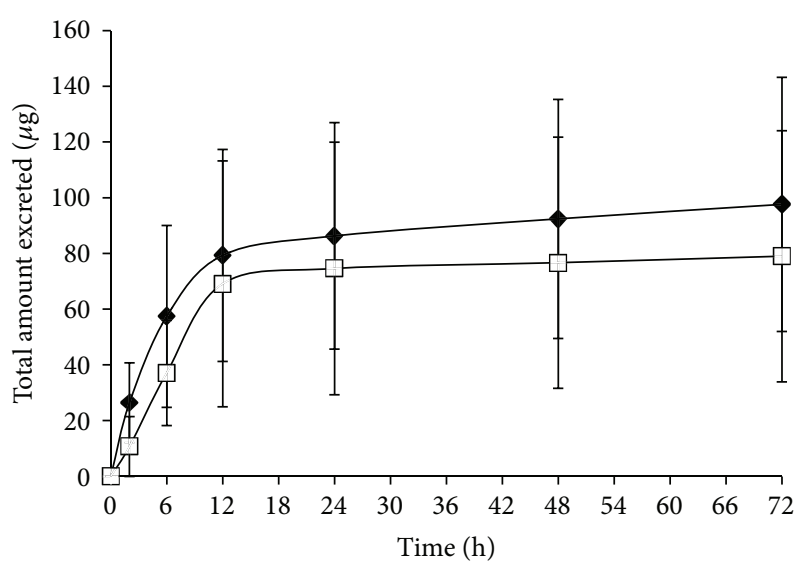

(a)

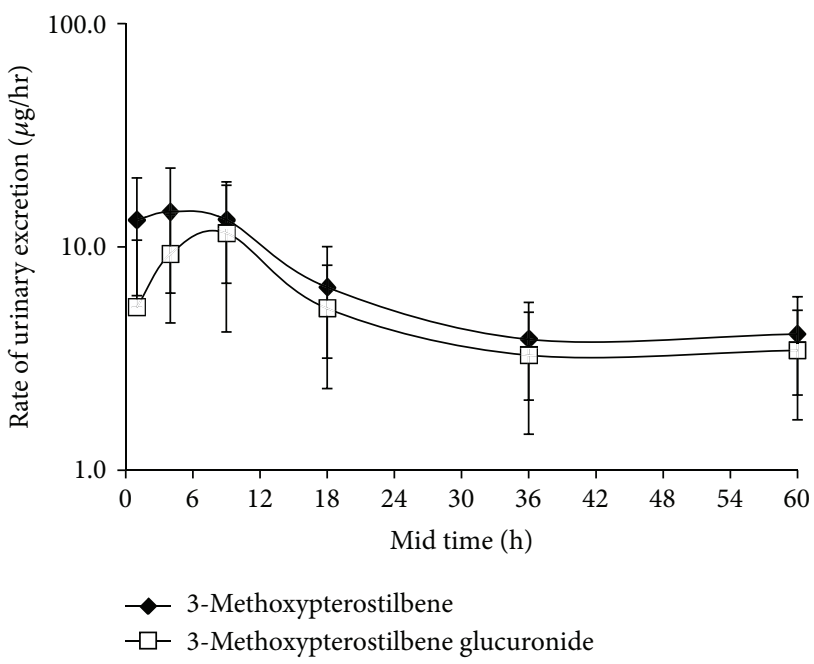

(c)

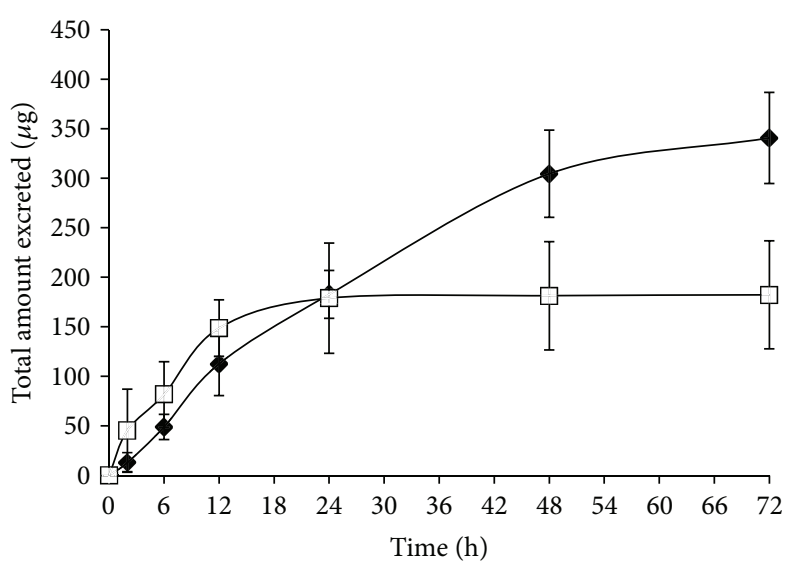

(b)

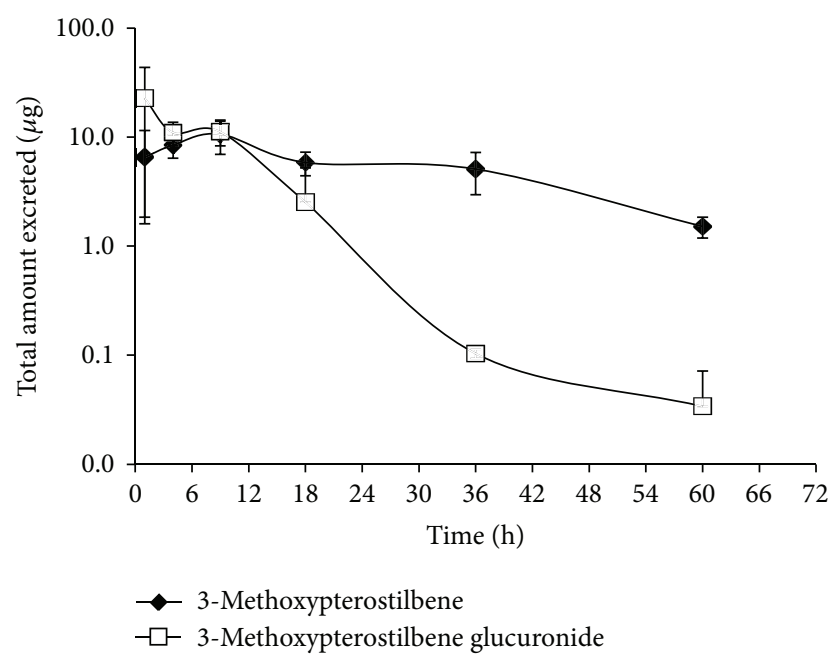

(d)

Figure 3: (a) Cumulative 3-methoxypterostilbene and glucuronidated metabolite ( $\mu \mathrm{g})$ excreted in urine over $72 \mathrm{~h}$ after intravenous administration. (b) Cumulative 3-methoxypterostilbene and glucuronidated metabolite ( $\mu \mathrm{g})$ excreted in urine over $72 \mathrm{~h}$ after oral administration. (c) Rate of excretion $(\mu \mathrm{g} / \mathrm{h})$ of 3-methoxypterostilbene and glucuronidated metabolite in urine over $72 \mathrm{~h}$ after intravenous administration. (d) Rate of excretion $(\mu \mathrm{g} / \mathrm{h})$ of 3-methoxypterostilbene and glucuronidated metabolite in urine over $72 \mathrm{~h}$ after oral administration $(n=4$ mean \pm SEM).

$1.64 \pm 0.950 \%$ for IV and $1.24 \pm 0.160 \%$ for PO, indicating that 3-methoxypterostilbene is mainly excreted via nonrenal routes. Renal clearance $\left(\mathrm{CL}_{\text {renal }}\right)$ was measured at $0.760 \pm 0.46 \mathrm{~L} / \mathrm{h} / \mathrm{kg}$ for IV and $0.0100 \pm 0.00100 \mathrm{~L} / \mathrm{h} / \mathrm{kg}$ for $\mathrm{PO}$, and hepatic clearance $\left(\mathrm{CL}_{\text {hepatic }}=\mathrm{CL}_{\text {total }}-\right.$ $\mathrm{CL}_{\text {renal }}$ ) was determined to be $47.1 \pm 23.3 \mathrm{~L} / \mathrm{h} / \mathrm{kg}$ for IV and $0.480 \pm 9.0800 \mathrm{~L} / \mathrm{h} / \mathrm{kg}$ for PO assuming that nonrenal clearance is hepatic clearance. The volume of distribution of 3-methoxypterostilbene is $5.11 \pm 0.380 \mathrm{~L} / \mathrm{kg} \mathrm{IV}$ and $52.0 \pm$ $10.0 \mathrm{~L} / \mathrm{kg}$ PO, which is greater than total body water, suggesting that 3-methoxypterostilbene is highly distributed into tissues. The mean area under the curve (AUC), representing the total amount of exposure in the serum over time, was $48.1 \pm 23.8 \mu \mathrm{g} \cdot \mathrm{h} / \mathrm{mL}$ for IV and $229 \pm 44.6 \mu \mathrm{g} \cdot \mathrm{h} / \mathrm{mL}$ for PO. The serum concentration of 3-methoxypterostilbene declined very slowly with a mean elimination half-life of $18.9 \pm 10.9 \mathrm{~h}$ for IV and $73.3 \pm 8.91 \mathrm{~h}$ for PO. The oral bioavailability for 3-methoxypterostilbene was determined to be $50.6 \% 0020 \pm$ $10.0 \%$.

Reported bioavailability of resveratrol in rats ranges from 20 to $38.8 \%$ [27, 32] and $<1 \%$ in humans [37] with a wide variability in pharmacokinetic parameters among individuals [38]. Species-dependent rapid conjugation with higher glucuronidation rates and affinity in humans may limit stilbene bioavailability and show expressed differences in pharmacokinetics between rodent and human studies. Poor bioavailability in humans is a potential limitation in the use of resveratrol as a therapeutic agent, hence the interest in structural analogs. 3-Methoxypterostilbene bioavailability in rats has been determined to be $50.6 \% \pm 10.0 \%$. The melting point range of 3-methoxypterostilbene was experimentally determined to be $88.5-91.2^{\circ} \mathrm{C}$. The reported melting point range of resveratrol is $253-255^{\circ} \mathrm{C}$ [39]. Therefore, 3-methoxypterostilbene has a lower crystallinity than 


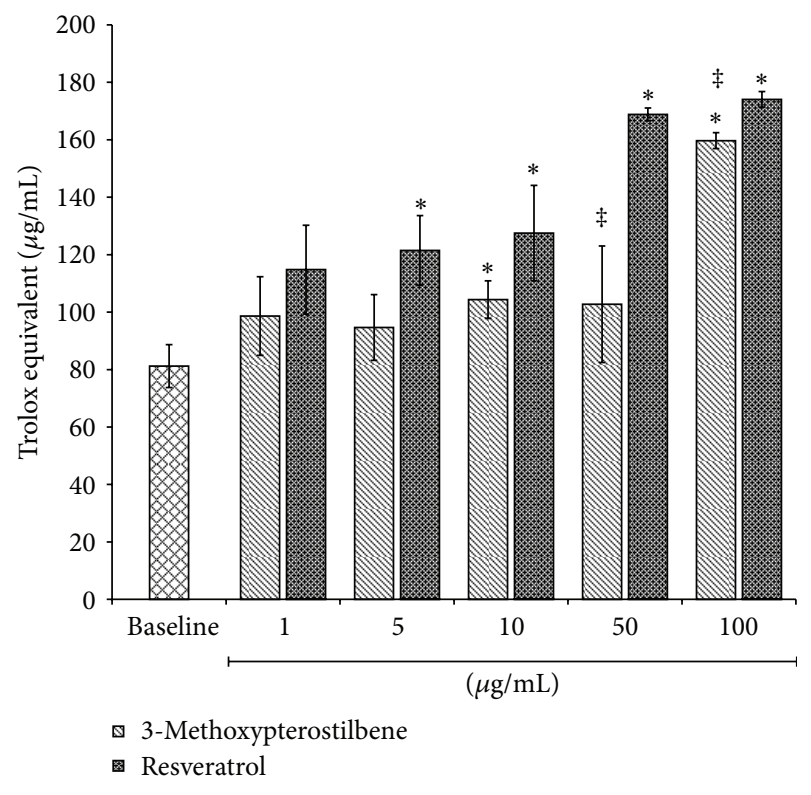

FIgURE 4: Antioxidant capacity $(n=4$, mean \pm SEM) of 3methoxypterostilbene and resveratrol at $1,10,50$, and $100 \mu \mathrm{g} / \mathrm{mL}$ dissolved in DMSO. * Significantly greater than baseline (DMSO) sample $(P<0.05)$. ${ }^{\ddagger}$ Significantly different from resveratrol at the same concentration $(P<0.05)$.

resveratrol. The low crystallinity of 3-methoxypterostilbene is responsible for its increased dissolution over resveratrol. Furthermore, the aqueous solubility of resveratrol is $\sim 30 \mathrm{mg} / \mathrm{mL}$ [40] and the predicted aqueous solubility, using AlogPs [41] of 3-methoxypterostilbene is $8-88 \mathrm{mg} / \mathrm{L}$. The increased bioavailability of 3-methoxypterostilbene in rats compared to resveratrol is likely due to its lower crystallinity resulting in enhanced dissolution over resveratrol and may be in part due to differences in solubility and absorbance mechanisms which will be examined in further studies. The increased bioavailability of 3-methoxypterostilbene over resveratrol in rats may extend to the greater bioavailability of 3-methoxypterostilbene than that of resveratrol in humans.

Analysis of urine samples for both routes of administration displayed the presence of the parent compound, 3-methoxypterostilbene and the glucuronidated metabolite previously identified in the serum (Figures $3(a)$ and $3(b)$ ). The total cumulative urinary excretion plot (Figure 3(a)) indicates that 3-methoxypterostilbene is excreted predominantly in the aglycone form for PO administration and almost equally in the aglycone and glucuronidated metabolite form for IV dosing. The glucuronidated metabolite appears to be mostly excreted by $12 \mathrm{~h}$ after dose for both routes of administration while 3-methoxypterostilbene (aglycone) appeared to be predominately excreted by $12 \mathrm{~h}$ after dose for IV but steadily increased in excretion even at $72 \mathrm{~h}$ after dose for $\mathrm{PO}$ administration. The half-life of 3-methoxypterostilbene in urine was determined to be $9.54 \pm 1.41 \mathrm{~h}$ for IV and $20.6 \pm 3.01 \mathrm{~h}$ for PO. The rate of urinary excretion plot (Figure 3(b)) indicates that 3-methoxypterostilbene and its glucuronidated metabolite have similar rates of excretion as indicated by their parallel slope $(-\mathrm{KE} / 2.303)$ for IV administration but the glucuronidated metabolite appears to have a greater rate of excretion over the aglycone after PO administration.

The total dose of 3-methoxypterostilbene administered was $10 \mathrm{mg} / \mathrm{kg}$ for IV and $100 \mathrm{mg} / \mathrm{kg}$ PO. The average weight of the rats in this experiment was $\sim 200 \mathrm{~g}$. Each rat received $\sim 2 \mathrm{mg}$ of 3-methoxypterostilbene IV and $20 \mathrm{mg}$ PO. The plots of cumulative amount excreted in urine for both the aglycone and glucuronidated metabolite forms excreted ( $\sim 98 \mu \mathrm{g}$ and $80 \mu \mathrm{g}$, resp., for IV and $341 \mu \mathrm{g}$ and $182 \mu \mathrm{g}$, resp., for PO) are very small compared to the overall dose administered $(\sim 2 \mathrm{mg}$ and $20 \mathrm{mg}$ for IV and PO, resp.). This further suggests that 3methoxypterostilbene is eliminated predominately by nonrenal routes. As previously mentioned, $f_{e}$ was $1.64 \pm 0.950 \%$ for IV and $1.24 \pm 0.160 \%$ for $\mathrm{PO}$, and therefore $\mathrm{CL}_{\text {renal }}$ was $0.760 \pm$ $0.460 \mathrm{~L} / \mathrm{h} / \mathrm{kg}$ for IV and $0.0100 \pm 0.00100 \mathrm{~L} / \mathrm{h} / \mathrm{kg}$ for PO. Excretion via nonrenal routes for 3-methoxypterostilbene agrees with literature reports of nonrenal excretion of other stilbenes $[27,30]$.

3.2. Content Analysis of Dried Traditional Chinese Medicinal Plants. Evaluation of the S. salsula extract and dried $R$. palmatum indicated that only the S. salsula extract contained detectable levels of 3-methoxypterostilbene. The aglycone concentration for the $S$. salsula extract was determined to be $0.842 \mu \mathrm{g} / \mathrm{g}$ and the total concentration of 3-methoxypterostilbene (aglycone and glycoside) was determined to be $0.853 \mu \mathrm{g} / \mathrm{g}$ indicating that 3-methoxypterostilbene exists primarily in its aglycone form in S. salsula extract. Despite the report that 3-methoxypterostilbene exists as an aglycone of a stilbene glycoside in $R$. palmatum [2], the compound was not detected as an aglycone or glycoside in the commercially available dried Chinese rhubarb. It is suspected that 3-methoxypterostilbene may be detectable in other commercially available Chinese rhubarb samples and that plant variation likely accounts for the lack of detection in this sample.

3.3. Antioxidant Capacity of 3-Methoxypterostilbene. Figure 4 reports the antioxidant capacity of 3-methoxypterostilbene in units of Trolox equivalents $(\mu \mathrm{g} / \mathrm{mL})$. The baseline (DMSO only) samples have a low antioxidant capacity (81.2 \pm $7.47 \mu \mathrm{g} / \mathrm{mL}$ or $0.325 \pm 0.0299 \mathrm{mM}$ ). 3-Methoxypterostilbene demonstrates a modest concentration-dependent antioxidant activity with an antioxidant capacity at $1 \mu \mathrm{g} / \mathrm{mL}$ of $98.6 \pm$ $13.7 \mu \mathrm{g} / \mathrm{mL}(0.394 \pm 0.0546 \mathrm{mM})$ Trolox equivalents and a capacity at $100 \mu \mathrm{g} / \mathrm{mL}$ of $174 \pm 2.70 \mu \mathrm{g} / \mathrm{mL}(0.695 \pm$ $0.00940 \mathrm{mM}$ ) Trolox equivalents. This indicated that 3methoxypterostilbene prevents oxidation at comparable levels to Trolox, if not better (as seen at lower concentrations). 3-Methoxypterostilbene demonstrated significantly greater activity to the baseline samples from 10 to $100 \mu \mathrm{g} / \mathrm{mL}(P<$ 0.05 ) and only showed significant difference from resveratrol activity at the two highest concentrations tested, 50 and $100 \mu \mathrm{g} / \mathrm{mL}(P<0.05)$. 


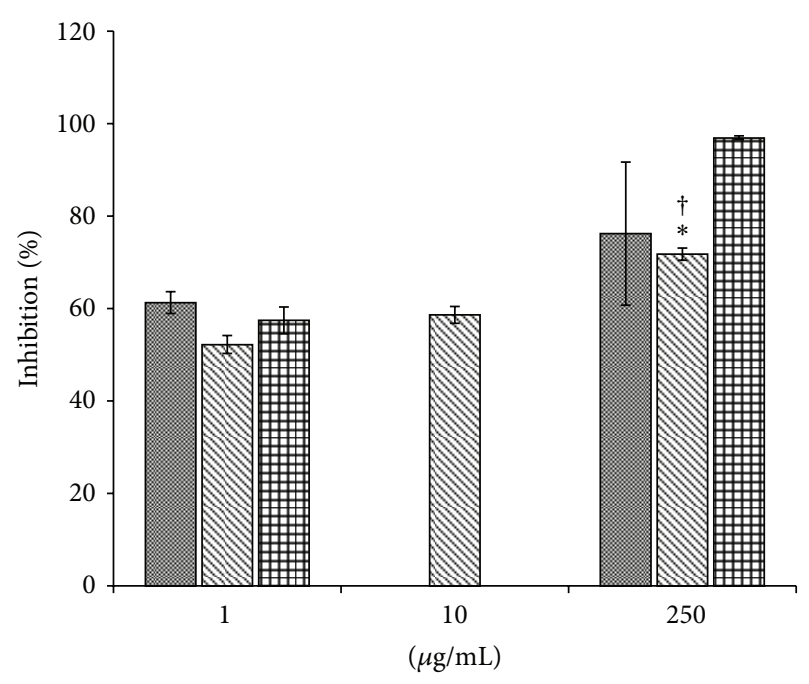

Ibuprofen

s 3-Methoxypterostilbene

口. Etodolac

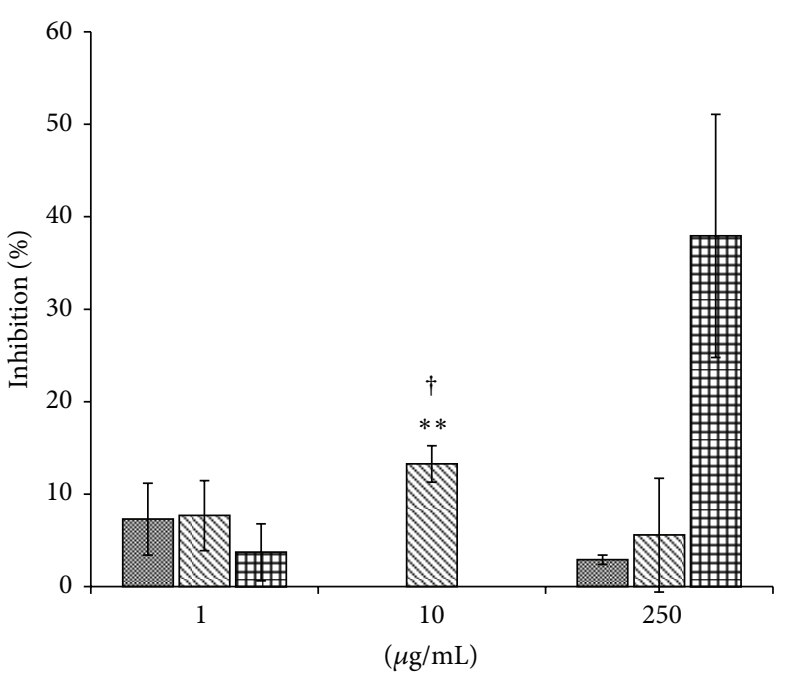

Ibuprofen 3-Methoxypterostilbene - Etodolac

(a)

(b)

Figure 5: (a) Cycloxoygenase I inhibition activity of 3-methoxypterostilbene at 1, 10, and $250 \mu \mathrm{g} / \mathrm{mL}$. (b) Cycloxoygenase II inhibition activity of 3-methoxypterostilbene at 1,10 , and $250 \mu \mathrm{g} / \mathrm{mL}$. ${ }^{*}$ Significantly greater activity than $1 \mu \mathrm{g} / \mathrm{mL}$ ibuprofen $(P<0.05) .{ }^{* *}$ Significantly greater activity than $250 \mu \mathrm{g} / \mathrm{mL}$ ibuprofen $(P<0.05)$. ${ }^{\dagger}$ Significantly greater activity than $1 \mu \mathrm{g} / \mathrm{mL}$ etodolac $(P<0.05)$. ${ }^{\ddagger}$ Significantly greater activity than $250 \mu \mathrm{g} / \mathrm{mL}$ etodolac $(P<0.05)(n=4$, mean \pm SEM $)$.

The ability of 3-methxoypterostilbene to work as an antioxidant is of paramount importance as the wide range of health benefits of polyphenols are thought to result at least in part from their antioxidant capacity. For example, the ability of resveratrol to limit the start and progression of atherosclerosis is associated with the compound's ability to inhibit lipid oxidation of polyunsaturated fatty acids [42]. It is likely that the health benefits of 3-methoxypterostilbene will also be associated with its antioxidant capacity. In the literature, it is well known that the number and position of the hydroxyl groups on stilbenes are critical for bioactivity and $t$ antioxidant activity [43-46]. A computer model of antioxidant activity of hydroxystilbenes suggests that 3methoxypterostilbene is one of the most potent 3,4 hydroxystilbenes modeled and has greater potency than resveratrol [47].

3.4. Cyclooxygenase Inhibitory Activity. Figure 5 reports the cyclooxygenase inhibitory activity of 3-methoxypterostilbene and two NSAIDs: etodolac and ibuprofen. 3-Methoxypterostilbene appears to have greater activity against COX-1 than COX-2. Figure 5(a) demonstrates the positive concentration-dependent inhibitory activity of 3-methoxypterostilbene against COX-1. While 3-methoxypterostilbene did not demonstrate significantly greater $(P<0.05)$ COX-1 inhibition activity than the two NSAIDs at lower concentrations, the high concentration $(250 \mu \mathrm{g} / \mathrm{mL})$ of 3-methoxypterostilbene demonstrated significantly greater activity $(P<0.05)$ than the NSAIDs at low doses. Figure 5(a) details the COX-2 inhibitory activity of 3-methoxypterostilbene. At the concentration of $10 \mu \mathrm{g} / \mathrm{mL}$, 3-methoxypterostilbene demonstrated statistically greater inhibition $(P<0.05)$ than etodolac at $1 \mu \mathrm{g} / \mathrm{mL}$ and ibuprofen at $250 \mu \mathrm{g} / \mathrm{mL}$. Several stilbenes, including resveratrol, are known to be preferential COX-2 inhibitors [28].

\subsection{Antidiabetic Activity}

3.5.1. Alpha-Glucosidase Activity. Figure 6 reports the alpha-glucosidase inhibition of 3-methoxypterostilbene and resveratrol. Resveratrol shows a clear positive concentrationdependent inhibition relationship whereas 3-methoxypterostilbene does not appear to exhibit greater inhibition at higher concentrations. $\alpha$-Glucosidase inhibition activity is only statistically different $(P<0.05)$ between the two stilbenes at the two highest concentrations tested (100 and $200 \mu \mathrm{g} / \mathrm{mL}$ ).

$\alpha$-Glucosidase is an enzyme found in the small intestine which hydrolyzes $1,4-\alpha$-bonds of disaccharides into glucose. Inhibition of $\alpha$-glucosidase suppresses postprandial hyperglycemia by lowering the rate of glucose absorption via delayed carbohydrate digestion and extended digestion time. $\alpha$-Glucosidase inhibitors are useful in maintaining glycemic control of prediabetic and type two diabetic patients. The lower concentrations of 3-methoxypterostilbene tested may be biologically achievable resulting in moderate inhibition of $\alpha$-glucosidase comparable to that of resveratrol, and reduction of postprandial hyperglycemia could be seen. 


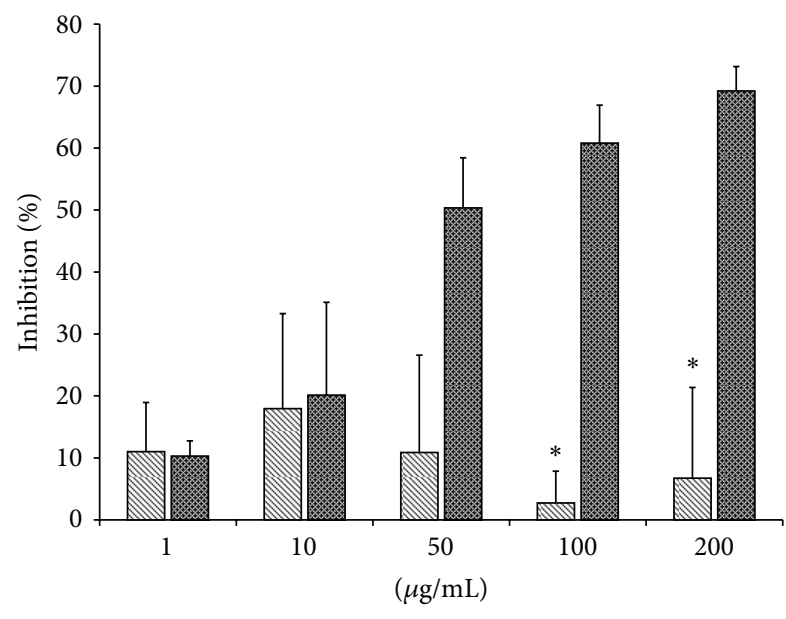

\$ 3-Methoxypterostilbene

图 Resveratrol

FIGURE 6: Alpha-glucosidase inhibition activity of 3-methoxypterostilbene and resveratrol $(n=6$, mean \pm SEM $) .{ }^{*}$ Significantly different from resveratrol at the same concentration $(P<0.05)$.

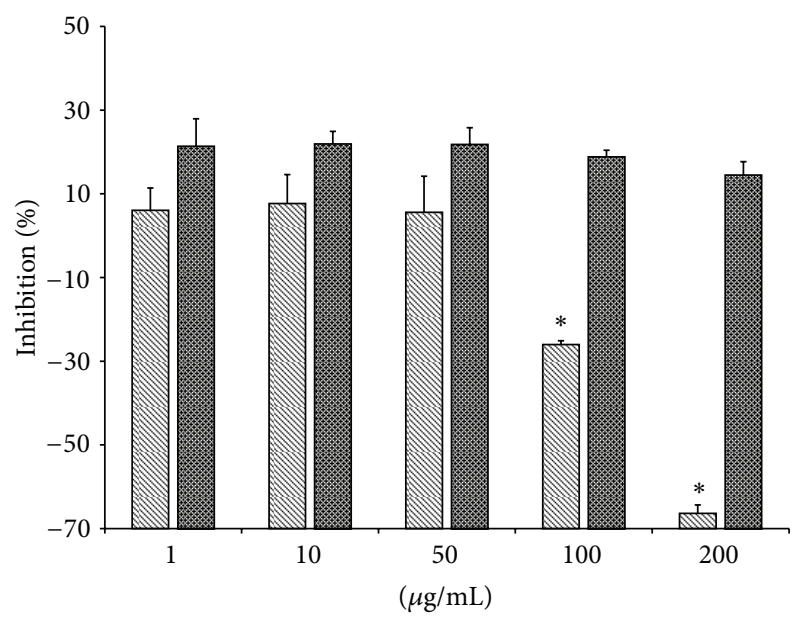

ه 3-Methoxypterostilbene

图 Resveratrol

FIGURE 7: Alpha-amylase inhibition activity of 3-methoxypterostilbene and resveratrol $(n=6$, mean \pm SEM $) .{ }^{*}$ Significantly different from resveratrol at the same concentration $(P<0.05)$.

3.5.2. Alpha-Amylase Activity. $\alpha$-Amylase inhibition activity by 3-methoxypterostilbene and resveratrol is shown in Figure 7. Both resveratrol and 3-methoxypterostilbene display relatively weak inhibition of $\alpha$-amylase, and both stilbenes show a slightly negative concentration inhibition relationship. At the highest concentrations tested, 3methoxypterostilbene appears to increase activity of $\alpha$ amylase. At lower, biologically relevant concentrations (1$50 \mu \mathrm{g} / \mathrm{mL}$ ), there is no significant difference between inhibition activity of 3-methoxypterostilbene and resveratrol.
In humans, $\alpha$-amylase is an enzyme predominately found in the pancreas and saliva. Like $\alpha$-glucosidase, $\alpha$-amylase hydrolyzes $\alpha$-1,4-glycosidic bonds but acts on polysaccharides. Inhibition of $\alpha$-amylase also reduces postprandial hyperglycemia, and $\alpha$-glucosidase inhibitors may be used to treat type 2 diabetes. The modest inhibitory activity of 3methoxypterostilbene at biologically relevant levels suggests that it may be as effective as resveratrol at helping reduce postprandial hyperglycemia.

\section{Conclusions}

In summary, the pharmacokinetics in rats and the in vitro metabolism of 3-methoxypterostilbene was evaluated for the first time. 3-methoxypterostilbene demonstrates improved bioavailability compared to resveratrol. 3-Methoxypterostilbene demonstrated antioxidant activity comparable to resveratrol at biologically relevant concentrations. This stilbene also showed strong COX-1 inhibition comparable to two NSAIDs and moderate inhibition of COX2. 3-Methoxypterostilbene demonstrated moderate antidiabetic activity via inhibition of $\alpha$-glucosidase and $\alpha$-amylase comparable to resveratrol. Further exploration of the pharmacodynamics of 3-methoxypterostilbene is under way to demonstrate utility in reducing postprandial hyperglycemia, adiposeness, cardiac hypertrophy and inflammation.

\section{Conflict of Interests}

The authors declare no financial conflict of interest.

\section{Acknowledgments}

The authors would like to acknowledge the University of Manitoba Graduate Fellowships from the University of Manitoba awarded to Stephanie E. Martinez and Casey L. Sayre, a Manitoba Graduate Scholarship awarded to Stephanie E. Martinez, a Pfizer Canada Centennial Pharmacy Research Award awarded to Stephanie E. Martinez and a Duff Roblin Fellowship to Casey L. Sayre. The authors would also like to thank the Sabina Corporation for their support.

\section{References}

[1] Z. J. Ma, X. Li, N. Li, and J. H. Wang, "Stilbenes from Sphaerophysa salsula," Fitoterapia, vol. 73, no. 4, pp. 313-315, 2002.

[2] Y. Kashiwada, G. I. Nonaka, I. Nishioka et al., "Studies on rhubarb (Rhei rhizome). XIV. Isolation and characterization of stilbene glucosides from Chinese rhubarb," Chemical and Pharmacetucial Bulletin, vol. 36, no. 4, pp. 1545-1549, 1988.

[3] M. T. Gill, R. Bajaj, C. J. Chang, D. E. Nichols, and J. L. McLaughlin, “3,3,5'-Tri-O-methylpiceatannol and 4,3'5'-tri-Omethylpiceatannol: improvements over piceatannol in bioactivity," Journal of Natural Products, vol. 50, no. 1, pp. 36-40, 1987.

[4] M. Roberti, D. Pizzirani, D. Simoni et al., "Synthesis and biological evaluation of resveratrol and analogues as apoptosisinducing agents," Journal of Medicinal Chemistry, vol. 46, no. 16, pp. 3546-3554, 2003. 
[5] R. Amorati, M. Lucarini, V. Mugnaini, G. F. Pedulli, M. Roberti, and D. Pizzirani, "Antioxidant activity of hydroxystilbene derivatives in homogeneous solution," Journal of Organic Chemistry, vol. 69, no. 21, pp. 7101-7107, 2004.

[6] V. Jerkovic, F. Nguyen, S. Nizet, and S. Collin, "Combinatorial synthesis, reversed-phase and normal-phase high-performance liquid chromatography elution data and liquid chromatography/positive atmospheric pressure chemical ionization tandem mass spectra of methoxylated and glycosylated resveratrol analogues," Rapid Communications in Mass Spectrometry, vol. 21, no. 15, pp. 2456-2466, 2007.

[7] H. S. Lee, B. W. Lee, M. R. Kim, and J. G. Jun, "Syntheses of resveratrol and its hydroxylated derivatives as radical scavenger and tyrosinase inhibitor," Bulletin of the Korean Chemical Society, vol. 31, no. 4, pp. 971-975, 2010.

[8] O. Vang, N. Ahmad, C. A. Baile et al., "What is new for an old molecule? systematic review and recommendations on the use of resveratrol," PLoS ONE, vol. 6, no. 6, article e19881, 2011.

[9] S. E. Martinez, C. L. Sayre, and N. M. Davies, "Analysis of 3methoxypterostilbene in biological fluids by high-performance liquid chromatography: application to pre-clinical pharmacokinetics," Biomedical Chromatography, vol. 27, no. 1, pp. 67-72, 2013.

[10] C. Privat, J. P. Telo, V. Bernardes-Genisson, A. Vieira, J. P. Souchard, and F. Nepveu, "Antioxidant properties of trans- $\varepsilon$ Viniferin as compared to stilbene derivatives in aqueous and nonaqueous media," Journal of Agricultural and Food Chemistry, vol. 50, no. 5, pp. 1213-1217, 2002.

[11] G. Kaur, M. Roberti, F. Raul, and U. R. Pendurthi, "Suppression of human monocyte tissue factor induction by red wine phenolics and synthetic derivatives of resveratrol," Thrombosis Research, vol. 119, no. 2, pp. 247-256, 2007.

[12] A. J. Gescher, "Resveratrol from red grapes-pedestrian polyphenol or useful anticancer agent?” Planta Medica, vol. 74, no. 13, pp. 1651-1655, 2008.

[13] I. G. Tsygankova and S. M. Zhenodarova, "The structureactivity correlation in a series of stilbene derivatives and related compounds, the inducers of apoptosis," Russian Journal of General Chemistry, vol. 81, no. 5, pp. 913-919, 2011.

[14] J. A. Baur, J. K. Pearson, N. L. Price et al., "Resveratrol improves health and survival of mice on a high-calorie diet," Nature, vol. 444, no. 7117, pp. 337-342, 2006.

[15] L. Rivera, R. Morón, A. Zarzuelo, and M. Galisteo, "Longterm resveratrol administration reduces metabolic disturbances and lowers blood pressure in obese Zucker rats," Biochemical Pharmacology, vol. 77, no. 6, pp. 1053-1063, 2009.

[16] M. Lagouge, C. Argmann, Z. Gerhart-Hines et al., "Resveratrol improves mitochondrial function and protects against metabolic disease by activating SIRT1 and PGC-1 $\alpha$," Cell, vol. 127, no. 6, pp. 1109-1122, 2006.

[17] J. Shang, L. L. Chen, F. X. Xiao, H. Sun, H. C. Ding, and H. Xiao, "Resveratrol improves non-alcoholic fatty liver disease by activating AMP-activated protein kinase," Acta Pharmacologica Sinica, vol. 29, no. 6, pp. 698-706, 2008.

[18] A. Gonzalez-Rodriquez, J. A. Mas Gutierrez, S. Sanz-Gonzalez et al., "Inhibition of PTP1B restores IRS1-mediated hepatic insulin signaling in IRS2-deficient mice," Diabetes, vol. 59, no. 3, pp. 588-599, 2010.

[19] J. P. Huang, S. S. Huang, J. Y. Deng, C. C. Chang, Y. J. Day, and L. M. Hung, "Insulin and resveratrol act synergistically, preventing cardiac dysfunction in diabetes, but the advantage of resveratrol in diabetics with acute heart attack is antagonized by insulin," Free Radical Biology and Medicine, vol. 49, no. 11, pp. 1710-1721, 2010.

[20] M. Thirunavukkarasu, S. V. Penumathsa, S. Koneru et al., "Resveratrol alleviates cardiac dysfunction in streptozotocininduced diabetes: role of nitric oxide, thioredoxin, and heme oxygenase," Free Radical Biology and Medicine, vol. 43, no. 5, pp. 720-729, 2007.

[21] P. Palsamy and S. Subramanian, "Resveratrol, a natural phytoalexin, normalizes hyperglycemia in streptozotocinnicotinamide induced experimental diabetic rats," Biomedicine and Pharmacotherapy, vol. 62, no. 9, pp. 598-605, 2008.

[22] G. Ramadori, L. Gautron, T. Fujikawa, C. R. Vianna, J. K. Elmquist, and R. Coppari, "Central administration of resveratrol improves diet-induced diabetes," Endocrinology, vol. 150, no. 12, pp. 5326-5333, 2009.

[23] J. C. Milne, P. D. Lambert, S. Schenk et al., "Small molecule activators of SIRT1 as therapeutics for the treatment of type 2 diabetes," Nature, vol. 450, no. 7170, pp. 712-716, 2007.

[24] K. K. R. Rocha, G. A. Souza, G. X. Ebaid, F. R. F. Seiva, A. C. Cataneo, and E. L. B. Novelli, "Resveratrol toxicity: effects on risk factors for atherosclerosis and hepatic oxidative stress in standard and high-fat diets," Food and Chemical Toxicology, vol. 47, no. 6, pp. 1362-1367, 2009.

[25] Y. H. Kim, Y. S. Kim, S. S. Kang, G. J. Cho, and W. S. Choi, "Resveratrol inhibits neuronal apoptosis and elevated $\mathrm{Ca}^{2+}$ / calmodulin-dependent protein kinase II activity in diabetic mouse retina," Diabetes, vol. 59, no. 7, pp. 1825-1835, 2010.

[26] M. Asensi, I. Medina, A. Ortega et al., "Inhibition of cancer growth by resveratrol is related to its low bioavailability," Free Radical Biology and Medicine, vol. 33, no. 3, pp. 387-398, 2002.

[27] J. F. Marier, P. Vachon, A. Gritsas, J. Zhang, J. P. Moreau, and M. P. Ducharme, "Metabolism and disposition of resveratrol in rats: extent of absorption, glucuronidation, and enterohepatic recirculation evidenced by a linked-rat model," Journal of Pharmacology and Experimental Therapeutics, vol. 302, no. 1, pp. 369-373, 2002.

[28] K. A. Roupe, C. M. Remsberg, J. A. Yáñez, and N. M. Davies, "Pharmacometrics of stilbenes: seguing towards the clinic," Current Clinical Pharmacology, vol. 1, no. 1, pp. 81-101, 2006.

[29] K. A. Roupe, J. A. Yáñez, X. W. Teng, and N. M. Davies, "Pharmacokinetics of selected stilbenes: rhapontigenin, piceatannol and pinosylvin in rats," Journal of Pharmacy and Pharmacology, vol. 58, no. 11, pp. 1443-1450, 2006.

[30] C. M. Remsberg, J. A. Yáñez, Y. Ohgami, K. R. Vega-Villa, A. M. Rimando, and N. M. Davies, "Pharmacometrics of pterostilbene: preclinical pharmacokinetics and metabolism, anticancer, antiinflammatory, antioxidant and analgesic activity," Phytotherapy Research, vol. 22, no. 2, pp. 169-179, 2008.

[31] S. Zhou, R. Yang, Z. Teng et al., "Dose-dependent absorption and metabolism of frans-polydatin in rats," Journal of Agricultural and Food Chemistry, vol. 57, no. 11, pp. 4572-4579, 2009.

[32] I. M. Kapetanovic, M. Muzzio, Z. Huan et al., "Pharmacokinetics, oral bioavailability, and metabolic profile of resveratrol and its dimethylether analog, pterostilbene, in rats," Cancer Chemotherapy and Pharmacology, vol. 68, no. 3, pp. 593-601, 2011.

[33] C. Y. Yang, S. Y. Tsai, P. D. L. Chao, H. F. Yen, T. M. Chien, and S. L. Hsiu, "Determination of hesperetin and its conjugate metabolites in serum and urine," Journal of Food and Drug Analysis, vol. 10, no. 3, pp. 143-148, 2002. 
[34] K. Tadera, Y. Minami, K. Takamatsu, and T. Matsuoka, "Inhibition of $\alpha$-glucosidase and $\alpha$-amylase by flavonoids," Journal of Nutritional Science and Vitaminology, vol. 52, no. 2, pp. 149-153, 2006.

[35] E. Wenzel and V. Somoza, "Metabolism and bioavailability of trans-resveratrol," Molecular Nutrition and Food Research, vol. 49, no. 5, pp. 472-481, 2005.

[36] N. M. Davies, J. K. Takemoto, D. R. Brocks, and J. A. Yáñez, "Multiple peaking phenomena in pharmacokinetic disposition," Clinical Pharmacokinetics, vol. 49, no. 6, pp. 351-377, 2010.

[37] T. Walle, "Bioavailability of resveratrol," Annals of the New York Academy of Sciences, vol. 1215, no. 1, pp. 9-15, 2011.

[38] M. Vaz-da-Silva, A. I. Loureiro, A. Falcao et al., "Effect of food on the pharmacokinetic profile of trans-resveratrol," International Journal of Clinical Pharmacology and Therapeutics, vol. 46, no. 11, pp. 564-570, 2008.

[39] A. Amri, J. C. Chaumeil, S. Sfar, and C. Charrueau, "Administration of resveratrol: what formulation solutions to bioavailability limitations?" Journal of Controlled Release, vol. 158, no. 2, pp. 182-193, 2012.

[40] "Resveratrol," Product information No. R5010, Sigma, Saint Loius, Mo, USA, 2013, http://www.sigmaaldrich.com/etc/ medialib/docs/Sigma/Product_Information_Sheet/1/r5050pis .Par. 0001.File.tmp/r5010pis.pdf.

[41] I. V. Tetko, J. Gasteiger, R. Todeschini et al., "Virtual computational chemistry laboratory-design and description," Journal of Computer-Aided Molecular Design, vol. 19, no. 6, pp. 453-463, 2005.

[42] L. Frémont, "Biological effects of resveratrol," Life Sciences, vol. 66, no. 8, pp. 663-673, 2000.

[43] S. Stojanović, H. Sprinz, and O. Brede, "Efficiency and mechanism of the antioxidant action of trans-resveratrol and its analogues in the radical liposome oxidation," Archives of Biochemistry and Biophysics, vol. 391, no. 1, pp. 79-89, 2001.

[44] J. G. Fang, M. Lu, Z. H. Chen et al., "Antioxidant effects of resveratrol and its analogues against the free-radical-induced peroxidation of linoleic acid in micelles," Chemistry, vol. 8, no. 18, pp. 4191-4198, 2002.

[45] Y. J. Cai, J. G. Fang, L. P. Ma, L. Yang, and Z. L. Liu, "Inhibition of free radical-induced peroxidation of rat liver microsomes by resveratrol and its analogues," Biochimica et Biophysica Acta, vol. 1637, no. 1, pp. 31-38, 2003.

[46] K. B. Harikumar and B. B. Aggarwal, "Resveratrol: a multitargeted agent for age-associated chronic diseases," Cell Cycle, vol. 7, no. 8, pp. 1020-1037, 2008.

[47] S. Rayne, C. D. Goss, K. Forest, and K. J. Friesen, "Quantitative structure-activity relationships for estimating the aryl hydrocarbon receptor binding affinities of resveratrol derivatives and the antioxidant activities of hydroxystilbenes," Medicinal Chemistry Research, vol. 19, no. 8, pp. 864-901, 2010. 


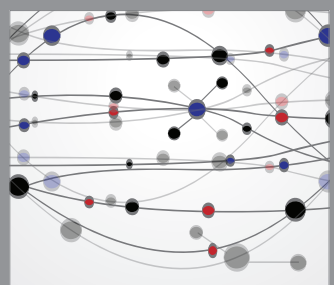

The Scientific World Journal
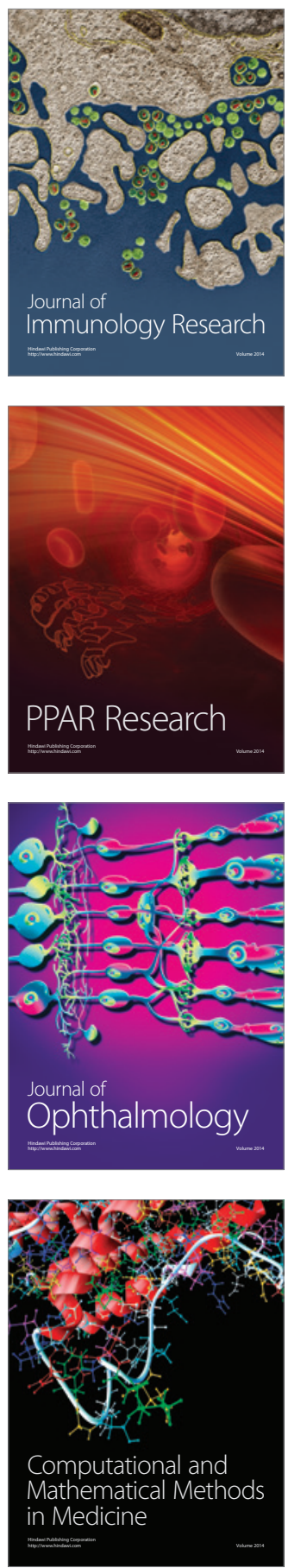

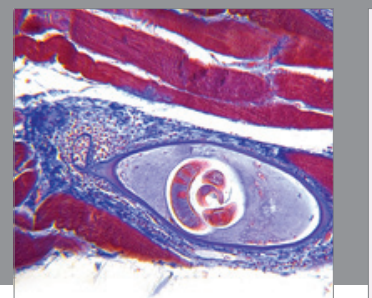

Gastroenterology

Research and Practice
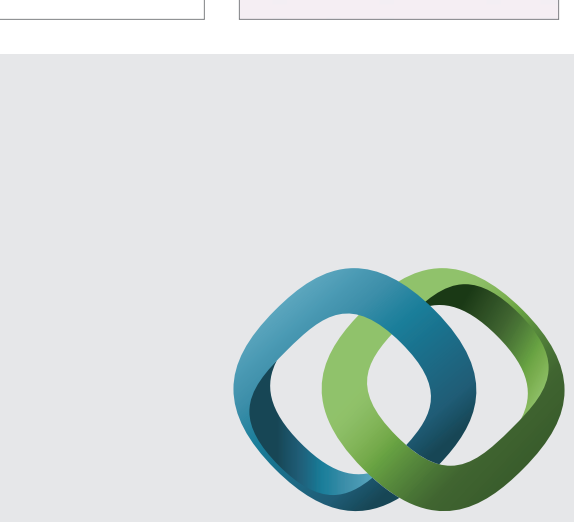

\section{Hindawi}

Submit your manuscripts at

http://www.hindawi.com
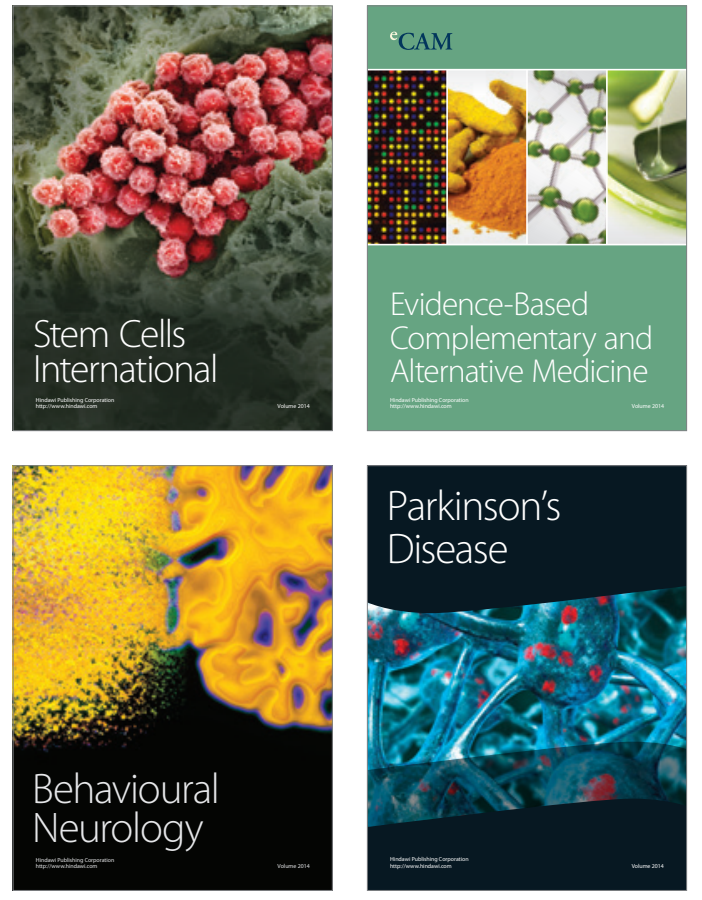
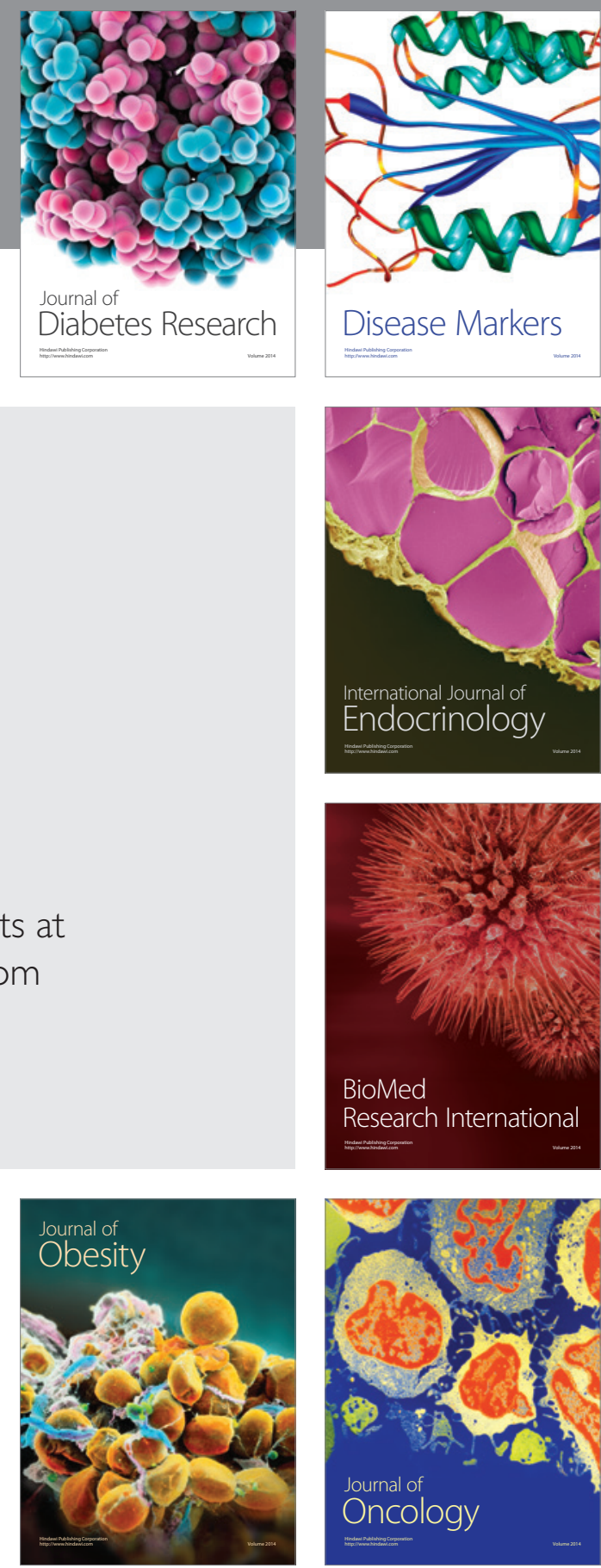

Disease Markers
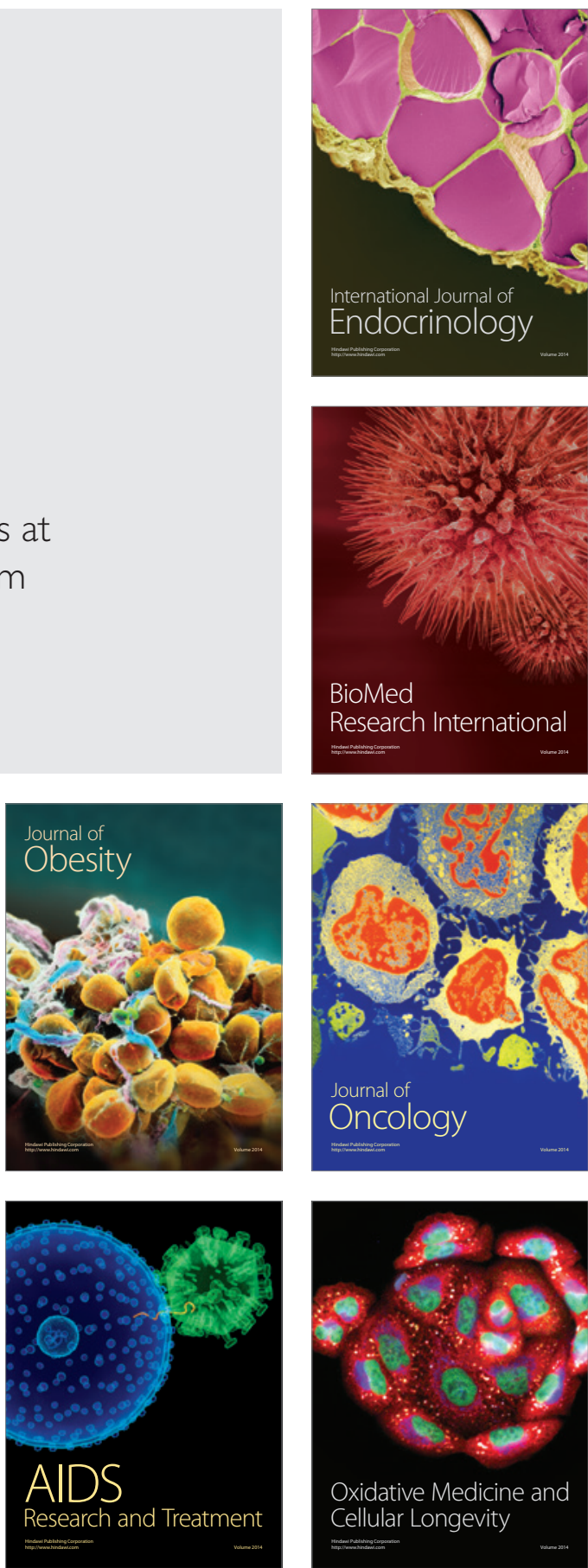